\title{
The Functional Analyze of the System for the Human Resource Management and Leadership Roles in the Albanian University Auditorium
}

\author{
Prof. Assoc. Dr. Alba Dumi \\ Dean of Graduated School, Ismail Qemali" Vlore University, Albania \\ Email: besi.alba@yahoo.com \\ Ma. Evisa Celo \\ Ismail Qemali" Vlore University, Albania1 \\ Email: evisa.celo@yahoo.com \\ Ma. Rezart Golemi \\ Ismail Qemali” Vlore University, Albania
}

Doi:10.5901/jesr.2013.v3n7p31

Abstract

This paper aims to succeed in mutual relationship of pedagogues as leadership and students. Speaking about the teacher as a pedagogical figure is such delicate and vast issue. Further more it brings into everybody's mind the first-teacher at elementary or someone else who is really different from the traditional teacher. The reason why l am focusing my article on the teacher (pedagogues) in University auditorium and their appraisals in relationship with the student is that, I frankly think that the traditional process of the teaching methods should change, during time, space and people themselves. Obviously radical changes need time and the causes are evident. Having a suggestive and psychological opinion on some of the problem during lessons and the relationship with the students is evident. Surely I don't pretend to give a solution to the problems risen up, but to be focused on such important point that should change. According to such ideas and my personal belief and experience I have followed an expression of Robert Ratherford, in the process of teaching "If the child (student) is not learning the way you are teaching,then you must teach in the way the child (student) learns!" In this article we intend to emphasize the role of leadership(teacher) based on our experience and the re-dimensioning of the world's knowledge in order to show the necessity of creating new models, aimed at preparing young specialist able to meet real world challenges.

Keywords: Leadership, Management relationship, Functional Analyze, Communication, University Auditorium

"Leadership is the art of accomplishing. More then science of managements says is possible" (Colin Powell)

\section{Introduction}

In many countries of Europe the public sector is going through a deep reformation. The most important element of this reform in the public sector is the incentive related to the reformation of the public administration. This process is necessary to face the challenges and to have better services with few sources possible.

The public services are oriented by the input. The structures and the organizational procedures are created in order to involve the employees and need efforts and contribution from them. In the public service department the results are considered as a product of the efforts and staff's capacities. The requirement of these results is lead by an inspirational vision, which is a clear mission and has some strategic aims, and these aims are transformed in objectives which aim to improve the performance. (Selznick, Philip. 1957)

Methodical culture is an art, skilful communication that is conditioned by the Leader (teacher) individuality, students or member of the group ability giving instruction, reviving interest in them for scientific knowledge and the ability to tolerate and understand the age and even the teenage actions. This culture requires from the teacher to organize the classes in such creative ways to attract students, because during the process of learning in school is not easy, but the elimination of such difficulties and achievements of the goals expressed in taking possession of the knowledge brings positivity and emotional state. (De Bruijn, H. 2002) We often hear the term Human Resource Management, Employee 
Relations and Personnel Management used in the popular press as well as by Industry experts.

\subsection{The general concept of HRM}

Whenever we hear these terms, we conjure images of efficient managers busily going about their work in glitzy offices. In this article, we look at the question "what is HRM?" by giving a broad overview of the topic and introducing the readers to the practice of HRM in contemporary organizations. (Robbins, S.P. 1998)

Though as with all popular perceptions, the above imagery has some validity, the fact remains that there is much more to the field of HRM and despite popular depictions of the same, the "art and science" of HRM is indeed complex. (Selznick, Philip. 1957)

We have chosen the term "art and science" as HRM is both the art of managing people by recourse to creative and innovative approaches; it is a science as well because of the precision and rigorous application of theory that is required.

\section{Literature Review and Hypotheses}

Rational persuasion involves the use of logical arguments and factual information to convince a target that the agent's request or proposal is feasible and consistent with shared objectives (Eagly \& Chaiken, 1984). This is a flexible tactic that can be used for influence attempts in any direction. Nevertheless, rational persuasion is likely to be used more in an upward direction that in other directions, because in an upward direction a manager is limited by a weaker power base and role expectations that discourage the use of some tactics (see discussion of other hypotheses). Directional differences for the use of rational persuasion were not consistent in three prior studies conduced with questionnaire (Erez et al...1986; Kipnis et al...1980; Yukl \& Falbe, 1990).
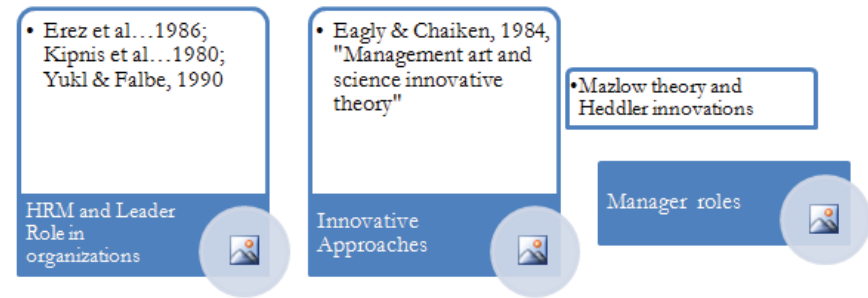

Tab 1: The indicators of HRM.Innovative and Approaches Source: HRM Theory Addler 2005

Agents reported greater use of this tactic in upward influence attempts, but directional differences were not found for targets. Results for the consequences of using rational persuasion have been inconsistent also. In the questionnaire study by Kipnis and Sshmidt (1988) managers who received the highest performance ratings had a profile in which rational persuasion was the dominant tactic for upward influence attempts. However rational persuasion was not related to successful upward influence in the questionnaire study by Mowday (1978). Likewise tactics involving aspects of rational persuasion were not related to outcome success in the four critical incident studies described earlier

\subsection{Research Goal and data collected}

The whole process involves all the working students in University auditorium, learning, express innovative ideas, conducting their project in their classes, in order to show up their achievement during the teaching process. Acknowledged development strategies given by the teacher and the evaluation of student scientific projects. During this process of implementing this strategy, the leadership role is based on rules and extreme strict responsibilities toward the students, in order to handle the unexpected difficulties and obstacles the work of all the students to achieve their goals and purposes. (De Bruijn, H. 2002)

$\mathrm{H}$ 2: The second definition of HRM encompasses the management of people in organizations from a macro perspective i.e. managing people in the form of a collective relationship between management and employees. This approach focuses on the objectives and outcomes of the HRM function. What this means is that the HR function in 
contemporary organizations is concerned with the notions of people enabling, people development and a focus on making the "employment relationship" ful-filling for both the management and employees. (Selznick, Philip. 1957) These definitions emphasize the difference between Personnel Management as defined in the second paragraph and human resource management as described in the third paragraph. (Robbins, S.P. 1998)

To put it in one sentence, personnel management is essentially "work-force" centered whereas human resource management is "resource" centered. The key difference is HRM in recent times is about fulfilling management objectives of providing and deploying people and a greater emphasis on planning, monitoring and control. (De Bruijn, H. 2002)

The hypothesis coming next:

2.1.1 H1.Learning process is difficult, but if someone(students themselves) is not given what is meant hard to resolve, human being never knows how far reaches.

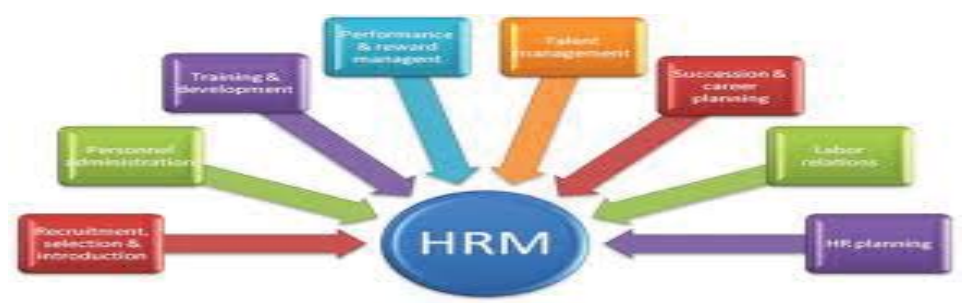

Tab1.3. The tolerance and the experience of daily relationship. (Selznick, Philip. 1957)

Often in everyday life student-teacher relationship is mutual and the leadership responsibility is high Regardless to the specifics that takes the position of teacher relations, fundamental is to be perceived as work relationship which are characterized by tolerant communications that runs through good will of understanding and bon-sense. Tolerantia=Patience (a Latin word)

\subsubsection{H 2:An important aspect of our daily work and educational learning, where there should be tolerance and to show the full comprehension, the superlative degree is that of controlling student knowledge possession.}

An active job situation, full of faith opportunities to students and an optimal concentration of teacher and students in learning process.Whatever the definition we use the answer to the question as to "what is HRM?" is that it is all about people in organizations. No wonder that some MNC's (Multinationals) call the HR managers as People Managers, People Enablers and the practice as people management. In the 21st century organizations, the HR manager or the people manager is no longer seen as someone who takes care of the activities described in the traditional way.

The performance evaluation of the employees has two objectives: Administrative objectives. It gives information in setting the salary, promotions, firing, and assures the necessary documentation to verify decisions in juridical processes.

The main objective is the objective of the development. The information can be used to diagnose the needs for trainings, career planning etc. the feedback and the training based on the information of the evaluation assures the fundaments for constant performance improvement. (Robins \& Couter, 1999) The performance evaluation is determined as an evaluation of the past and actual performance of an employee that works in accordance with the performance standards of the organization. In fact, most organizations have different departments dealing with Staffing, Payroll, and Retention etc. Instead, the HR manager is responsible for managing employee expectations vis-à-vis the management objectives and reconciling both to ensure employee fulfillment and realization of management objectives.

Tab 1: Traditional concept, Staffing, Payroll, Retention

\begin{tabular}{|c|l|l|c|}
\hline $\begin{array}{c}\text { Consistency Of The Leader } \\
\text { Objectives (Instructor) }\end{array}$ & \multicolumn{1}{|c|}{ Traditional Concept } & \multicolumn{1}{|c|}{ Contemporary Concept } & Expectations \\
\hline Teaching & Acquisition of knowledge & Coordination of knowledge & $60-70 \%$ \\
\hline Knowledge & Are they absolute..? & Knowledge built on consciously & $60 \%$ \\
\hline
\end{tabular}




\begin{tabular}{|c|l|l|c|}
\hline Students & $\begin{array}{l}\text { We all learn the same way and not all } \\
\text { are able to learn better. }\end{array}$ & $\begin{array}{l}\text { Different students learn in } \\
\text { different ways but not all are } \\
\text { able to learn. }\end{array}$ & $60 \%$ \\
\hline Pedagogue(instructor) & provides insight(knowledge) & $\begin{array}{l}\text { Assists in the process of } \\
\text { transmitting knowledge }\end{array}$ & $70 \%$ \\
\hline University & $\begin{array}{l}\text { Equip students with Diploma for job } \\
\text { roles in society. }\end{array}$ & $\begin{array}{l}\text { a) Develop intelligent opinion. } \\
\text { b) does independent work for } \\
\text { the improvement of personal } \\
\text { and social life of the student }\end{array}$ & $70 \%$ \\
\hline $\begin{array}{c}\text { Scientific Establishment } \\
\text { and Leadership } \\
\text { management }\end{array}$ & $\begin{array}{l}\text { a) Citizens who know science. Leader } \\
\text { roles } \\
\text { b) Use science in everyday life. } \\
\text { Leader indiferent } \\
\text { c) use professional training in } \\
\text { decision-making leadership and } \\
\text { promoting roles }\end{array}$ & $\begin{array}{l}\text { a) Individuals form using the } \\
\text { method of scientific research to } \\
\text { solve problems. } \\
\text { b) Interest and the extraction } \\
\text { method highlighting critical } \\
\text { defects to achieve success. }\end{array}$ & $80 \%$ \\
\hline $\begin{array}{c}\text { Social formation and multi- } \\
\text { cultural influence }\end{array}$ & $\begin{array}{l}\text {-Position held in the protection of } \\
\text { identities and multi cultures. }\end{array}$ & $\begin{array}{l}\text { a) Influential in developing and } \\
\text { integrating it successfully in the } \\
\text { European elite leadership } \\
\text { b) suitability for employment } \\
\text { abroad }\end{array}$ & $62 \%$ \\
\hline
\end{tabular}

\section{Methodology and Research Goal}

But in requiring such strategy is always meant to be achievement of the mission. The other reason is that of 'all inclusion' in which elementary student can surely take advantages on behalf of good student. Hence, this results and concludes strategies and techniques that build on students' expectation for success while giving the right space, including security and real opportunity to learn right.

\subsection{Analyzing data and questionaries}

The performance evaluation is mainly characterized by qualitative indicators and there are only a few quantitative indicators. According to the data collected from the questionnaires the employees asses the importance of the performance evaluation in $100 \%$, they concretize it with the objectivity in the evaluation. To the question "Is the performance evaluation objective in your institution?"- $20 \%$ answered positively, $54 \%$ avoided the answer and $26 \%$ of them think that it is dictated from the subjectivity of the leaders. According to the questionnaire the major part of the questioned employees think that the performance evaluation takes to conflicts between the subordinate and the superiors. This is also another factor that contests rewarding according to the performance.

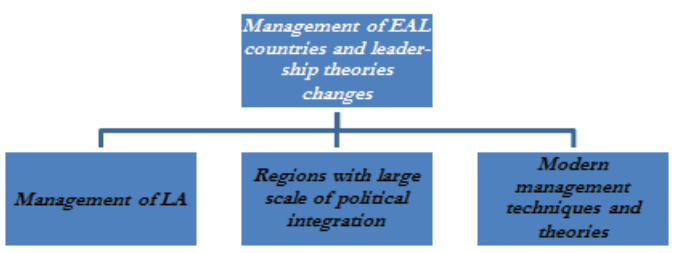

Tab 2. Management transfer to poor countries, Source: Jon Stuart Mill, 1989

\subsubsection{The Role of the Manager and "walk to walk" theory (Hence \&Blunner 2009)}

The manager has a duty to ensure that his or her management of the employees is free of biases and prejudices. It's been the case across industries and verticals where the employees feel discriminated against leading to attrition, lower employee morale and in the extreme cases, lawsuits against the company. Hence, the manager has to "walk the talk" and not simply pay lip service to the company's policies on employee performance. (De Bruijn, H. 2002) During the course of working together as a team, there are bound to be instances where friction between the manager and the team 
and within the team manifests itself. It is incumbent upon the manager to ensure that this does not morph into a corrosive effect that threatens the very existence of the team.

$$
\begin{aligned}
& \lim _{n \rightarrow \infty}\left(1+\frac{1}{n}\right)^{n} \text { in a1choise to an frictions } \\
& \mathrm{R}_{10}=(6+7+8+9)^{\mathrm{n}}+(1+2+3+\mathrm{N})^{\mathrm{n}+1} \\
& \mathrm{M}_{\mathrm{R}}=\frac{n 1(n 1+n 2+1)}{2}=\frac{4(4+5+1)}{2}=20
\end{aligned}
$$

We calculate the quadratic average derivation of the Man Whitney and Roddler criteria

$$
\mathrm{S}_{\mathrm{R} 1}=\sqrt{\frac{n 1 n 2(n 1+n 2+1)}{12}}=\sqrt{\frac{4.5(4+5+1)}{12}}=4.8
$$

A similar picture emerges in relation to leadership development activities. Lack of clarity about what makes leaders effective is reflected in lack of clarity about what makes leadership development programmes effective. The two key challenges facing the public sector in creating a strong supply of effective leaders are:

- Effective recruitment for leadership, whether recruiting people to take on major leadership roles, or at lower levels as future leaders;

- Developing leaders effectively, to bring out the potential of those who will take key leadership roles in future.

Tab 3: The indicators of developing leaders effectively.

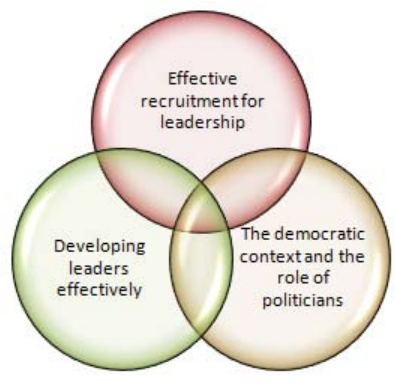

Source: PSEF and HR Strategic research 2012

Tackling these two challenges is the subject of this paper research. The hypothesis of this paper should expand and strengthen the Public Service Employer's Forum (PSEF) as an HR strategic forum to take forward recommendations of this report and to improve recruitment, retention and strengthening leadership in the public sector development for leaders across the public service over 2001-2003. Further work is required on the funding of this work programme. Relationships between politicians and officials can promote leadership. The democratic context and the role of politicians is one of the distinguishing characteristics of the public sector. Politicians do not just set the current framework of control within which public services are delivered.

\subsection{Sample and Data Collection}

They are also leaders in their own right. Government ministers are accountable for public service delivery to parliament and to the wider electorate. Local political leaders are accountable to their local electorates. Both local and national leaders have a mandate to deliver the policies in their manifestos. (Robbins, S.P. 1998)

The relationship between political and executive leadership is critical to the quality of public service delivery, and there are concerns at all levels about the quality of these relationships. Many leaders at the project workshops saw their relationship with politicians as one-way: one described it as a "master-servant" relationship. Greater clarity in the respective roles of politicians and managers was recognised as one of the keys to better service delivery in the recent Public Service Productivity Panel report, Meeting the Challenge. 


\subsubsection{Methodology and Analyze of Models of Leadership}

Methodology and Analyze of Models of Leadership cross the range of factors that motivate people, it is increasingly clear that the public sector needs to rethink the offer it makes to its employees. Implicitly, the "old deal" for public service employment:

- Relied on people wanting to work in jobs and for organisations concerned with serving the public good;

- Required and valued significant amounts of professional skill, particularly in human services (medicine, social work, etc);

- Set public service pay at adequate but never trend-setting levels; gave high protection through unionisation; (Dessler, G. 2000) Offered generally good pensions, benefits and job security, but limited prospects for promotion, which was generally slow; and provided limited flexibility in compensation and no direct link between pay and performance.

\subsection{The Role of the Employee}

The above section looked at the role of the manager. The manager has a duty to manage the team effectively and so does the employee have corresponding responsibilities as well. Absenteeism, Shirking Work, A negative attitude and a blasé approach to work are some things that the employee must avoid. It is helpful to the employee to know that once he or she is categorized as having an attitude problem, then it would be difficult for the employee to break the perception and perform effectively. (De Bruijn, H. 2002) This does not mean that the employee has to take whatever comes his or her way. The point here is that the employee must use the channels available for redressal instead of sulking at work if he or she has grievances about the manager. (Robbins, S.P. 1998)

\subsection{Organizational Focus and other countries experiences.}

Though the role of the HR manager and the organization seems to be relatively small, it is a fact that organizational goals and culture play a very important part in ensuring that employee performance is managed to the benefit of the organization. Most of us have read about or heard the benefits of working for MNC's (Multinational Companies) in India. The reason why they are highly talked about is the perception among potential and aspiring employees that these companies treat their people well. (Dessler, G. 2000)Though the point here is not to belittle Indian companies, the objective of this section is to highlight the ways in which organizations can shape the treatment of people in theory and practice. For anyone who is part of school education is clear that the task of teachers is a complex task, which has to do with her professional partnership as teachers, educators, civic and parent. (Robbins, S.P. 1998)

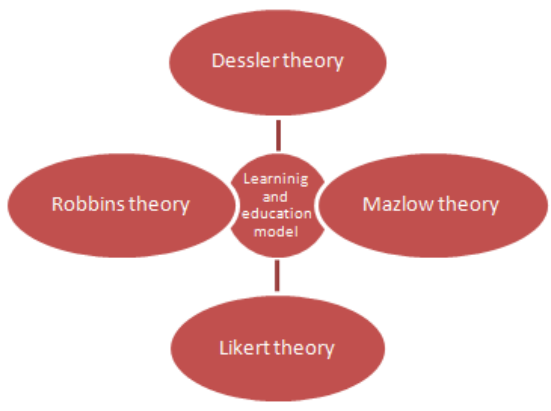

Graph 4: The process of daily educational- teaching to varied forms of pedagogy

The main possession is occupied by learning and education. In the process of daily educational- teaching the significance goes to varied forms of pedagogy, which are reflected in the ways of communication with (students). Dominance in the class of one emotional tone and respect over students personality in different classes, the close attitudes, kind and warm up to the level of parental attitudes, manifest of beliefs and respect toward their abilities to achieve better results ,can be expressed very well with the words "Understanding and tolerance." M Bardhyl (Tirane 
2003 219-220).In teacher's daily work and should prevail as possible a diverse culture with someone who is an integral part of pedagogical culture. Methodical culture is art, skilful communication that is conditioned by individuality of every teacher, ability to give student lessons, to revive interest in them for scientific knowledge, and ability to tolerate and understood and that their teenage acts. (Dessler, G. 2000)

This culture requires teacher's class organization in a creative and attractive way. During the process of learning in school, the process is not easy and simple, but the elimination of difficulties, the achievement of the goals expressed in possession of knowledge brings a positive emotional state. We have devoted a separate section on gender sensitization because when compared to other issues in managing diversity, this is the most pressing issue because of the preponderance of women in the workforce as well as recent trends that point to the emergence of this single issue as the dominant issue that is taking the mind space of managers. (Robbins, S.P. 1998)

The worrying aspect about this issue is that despite policies and rules governing gender specific issues in most organizations, there is little evidence to show that they are being followed. Hence, what is needed is a mindset change rather than more policies and this can only be done if the workforce is sensitized to the needs of women. (Dessler, $G$. 2000)

\section{Conclusions and recommendations}

The results from this article show that the performance evaluation is a very important element in the Public Administration, and it effects the improvement of the work in the state and central bodies.

- The performance evaluation conditions the emplacement and the implementation of the standards as referential points. Emplacing standards would increase the responsibility for each post in the Public Administration and will help in monitoring the performance of the institution.

\section{References}

Dessler, G. 2000. "Human Resource and Management. 8thedition. New Jersey: Prentice Hall International, Inc. De Bruijn, H. 2002"Managing Performance in the Public Sector'. London: Routledge.

Robins, S.P. and Couter, M. 1999.Management. 6 New Jersey: Prentice-Hall.

Dessler, G. 2000. "Human Resource Management.New Jersey: Prentice Hall International, Inc.

Robbins, S.P. 1998. Organizational Behavior: Concepts, Controversies, Applications.New Jersey: Prentice Hall.

International health reforming methodology, Belishova publish year 2007, pp 12

The National Strategy for Socio-Economic Development (NSSED)

Hoering, Uwe. 2002. Public Private Partnerships in the Water Sector Deutsche fur international Albania public sector reforming, pp 45,46

$\mathrm{MOH}$ analyze international conference, June 12 year 2010, pp 11-14 MOH and progressing Albanian Economy

MOF analyze international report year 2011, pp19-25 UNICEF pp 12

MOF \&USAID Financial report 2011, pp 37-39

Theodorakis PN, Benton Jl, Anderson JP, Glaros D, Trell E, Lionis C A comparative study of two primary health care practices on the Greek-Albanian border: 51st European General Practice Research, 2008

Workshop on research of general practice in transitional environment, Albania case study.Dumi Alba.Zagreb, Oct 19-22, 2000 (abstr).

Theodorakis P, Lionis C, Seniorou M, Kosta J, Trell E, Glaros D. Primary health services in southern Albania: current situation and perspective. 6th European Conference on General Practice and public administration Vienna, Jul 2-6, 2000

Provision of medical, pharmaceutical and hospital care to foreigners, no 8992/13-7-2000. Ministerial decree: Greek Ministry of Health and Welfare, 2000.

Barbullushi M, Koroshi A, Tase M. Albanian contribution to the treatment of refugee renal patients from Kosovo. Nephrol Dial Transpl 2000; 15: 1261

Selznick, Philip. 1957. Leadership in Administration: A Sociological Interpretation. New York: Harper \& Row. 